\title{
IL-4 Receptor Signaling Is Required for Mannose Receptor Expression by Macrophages Recruited to Granulomata but not Resident Cells in Mice Infected with Schistosoma mansoni
}

\author{
Sheena A. Linehan, Patricia S. Coulson, R. Alan Wilson, Adrian P. Mountford, \\ Frank Brombacher, Luisa Martínez-Pomares, and Siamon Gordon
}

Sir William Dunn School of Pathology (SAL, LM-P, SG), South Parks Road, Oxford, Department of Biology (PSC, RAW, APM), University of York, York, and Department of Infectious Diseases (SAL), Centre for Molecular Microbiology and Infection, Imperial College School of Medicine, London, United Kingdom; and Department of Immunology (FB), University of Cape Town, Groote Schuur Hospital, Cape Town, South Africa

SUMMARY: High levels of mannose receptor (MR) expression and pinocytic activity are a hallmark of Th2 cytokine-driven alternative M $\Phi$ activation in vitro. We examined expression of MR in situ and its regulation by Th1/Th2 cytokines in IL-4R $\alpha-/-$ and wild-type (WT) mice challenged with Schistosoma mansoni. Parasite eggs induce a vigorous granulomatous response, driven by Th2 cytokines in WT mice, but by Th1 cytokines in IL-4R $\alpha-/-$ mice. MR was expressed by granuloma M $\Phi$ in WT mice but not in IL-4R $\alpha-/-$ mice, whose M $\Phi$ nevertheless exhibited a mature phenotype and morphology. By contrast expression of MR in resident tissue M $\Phi$ and endothelial cells appeared unaffected by Th1/Th2 cytokines. Our results revealed that Th1/Th2 cytokines differentially regulate MR according to cell type and play a critical role in regulating MR expression by M $\Phi$ recruited to granulomata. We also present evidence that components of schistosome eggs and a fraction of their secretions are ligands of MR, and suggest that MR activity may be of functional significance in the granulomatous response. (Lab Invest 2003, 83:12231231).

$\Gamma^{\mathrm{h} 1}$ and Th2 cytokines both have potent effects on the function of $M \Phi$. Classic activation of $M \Phi$, mediated by Th1 cytokines, typically promotes secretion of proinflammatory cytokines, up-regulation of $\mathrm{NO}$ and $\mathrm{O}^{-}$production, and enhances the capacity of $M \Phi$ to activate primed $T$ cells. In contrast Th2 cytokines induce a different profile of changes in $\mathrm{M} \Phi$, known as alternative activation. Such $M \Phi$ secrete anti-inflammatory cytokines, generate low levels of toxic radicals, and have antigen-specific and nonspecific immunosuppressive properties (Goerdt and Orfanos, 1999; Gordon, 2003). Alternatively activated M $\Phi$ were first described by Stein et al (1992), who treated cultured murine M $\Phi$ with IL-4 and found that this Th2

\section{DOI: 10.1097/01.LAB.0000081392.93701.6F}

Received May 9, 2003.

This work was supported by Grant No. G0525 from the Arthritis Research Campaign and a Junior Research Fellowship from St. Cross College, Oxford (SAL). Support was also received from the UNDP/World Bank/WHO Special Program for Research and Training in Tropical Diseases (PSC, RAW), and Program Grant No. G8303179 from the Medical Research Council, United Kingdom (SG).

Address reprint requests to: Dr. Sheena Linehan, Department of Infectious Diseases, Centre for Molecular Microbiology and Infection, Imperial College School of Medicine, Armstrong Road, London, SW7 2AZ, United Kingdom.E-mail:s.a.linehan@ic.ac.uk cytokine did not simply deactivate $M \Phi$ but caused a strong induction of mannose receptor (MR) expression and endocytic activity.

The concept of the alternatively activated $\mathrm{M} \Phi$ has been extended to $M \Phi$ participating in Th2 reactions in vivo, particularly in parasitic infections, but it remains a challenge to distinguish phenotypically between $M \Phi$ of different activation states and resident tissue $M \Phi$ (Gordon, 2003). The contribution of Th2 cytokines to expression of putative $M \Phi$ alternative activation markers can be more readily addressed in murine infection models than in human disease. Alternatively activated M $\Phi$ recruited to the peritoneum by implanted Brugia malayi or Trypanosoma brucei brucei parasites express high levels of the eosinophil chemotactic factor, ECF-L/Ym1, and the resistin homolog, FIZZ1/RELM- $\alpha$ (Falcone et al, 2001; Raes et al, 2002). In the trypanosome infection model, up-regulation of these genes was found to be dependent on IL-4 and could be modeled by IL-4 treatment of cultured M $\Phi$ (Raes et al, 2002). There are few other examples of phenotypic markers of alternative $\mathrm{M} \Phi$ activation, which has contributed to the difficulty of studying these cells in vivo.

The differential regulation of MR in vitro by Th1/Th2 cytokines has been extensively characterized both in murine and human MФ (Doyle et al, 1994; Mokoena and Gordon, 1985; Montaner et al, 1999; Schreiber et al, 
1993; Stein et al, 1992), but studies addressing the expression and relevance of MR in Th2 responses in vivo have hitherto been lacking. MR is expressed by mature $\mathrm{M} \Phi$ but not monocytes. In the naïve mouse, resident tissue $\mathrm{M} \Phi$ of most nonlymphoid organs, restricted subsets of $М \Phi$ within lymphoid organs, and hepatic and lymphatic endothelial cells are positive for MR (Linehan et al, 1999; Takahashi et al, 1998). MR is a pinocytic and phagocytic receptor, with a broad ligand specificity for carbohydrate structures bearing terminal D-mannose, L-fucose, N-acetyl-D-glucosamine, and D-glucose
(Pontow et al, 1992). These include eukaryotic highmannose, some hybrid and terminally fucosylated $\mathrm{N}$-glycans, and an assortment of microbial polysaccharides, glycoproteins, and glycolipids. Studies on the phagocytosis of microbes by cultured $M \Phi$ and MR transfected COS-1epithelial cells have implicated MR in phagocytosis of the pulmonary pathogens, Pneumocystis carinii, Klebsiella pneumoniae, Mycobacterium tuberculosis, and Pseudomonas aeruginosa, and yeasts including the opportunistic pathogen, Candida albicans (Linehan et al, 2000). Phagocytosis mediated

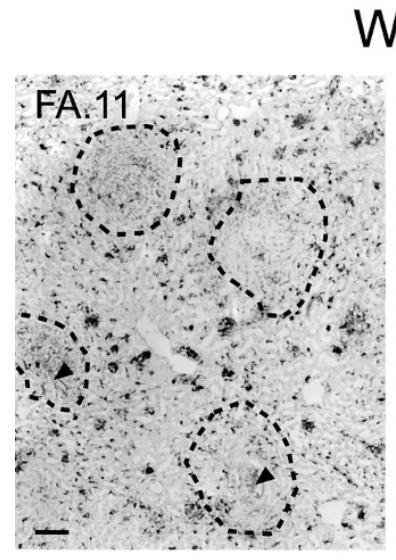

WT
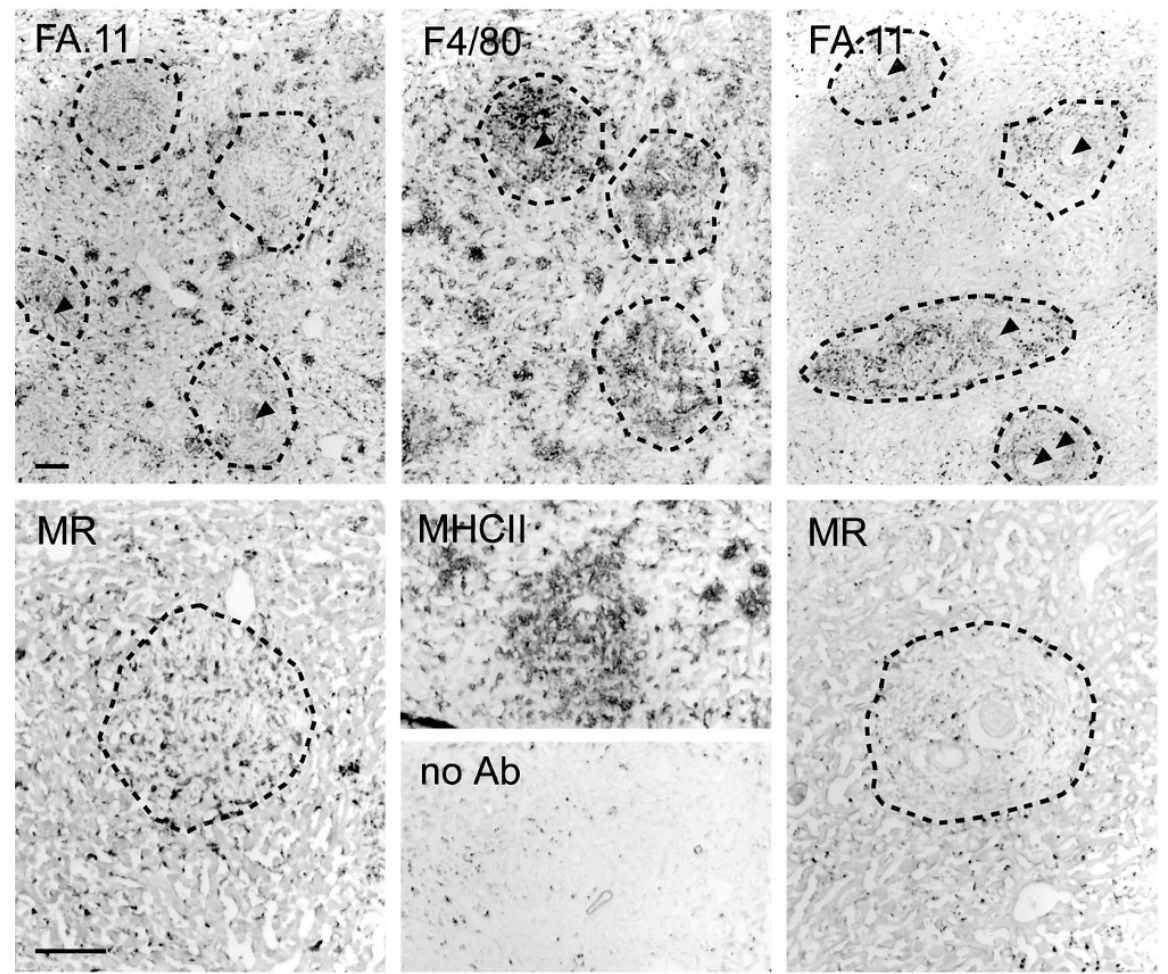

IL4R $\alpha-/-$
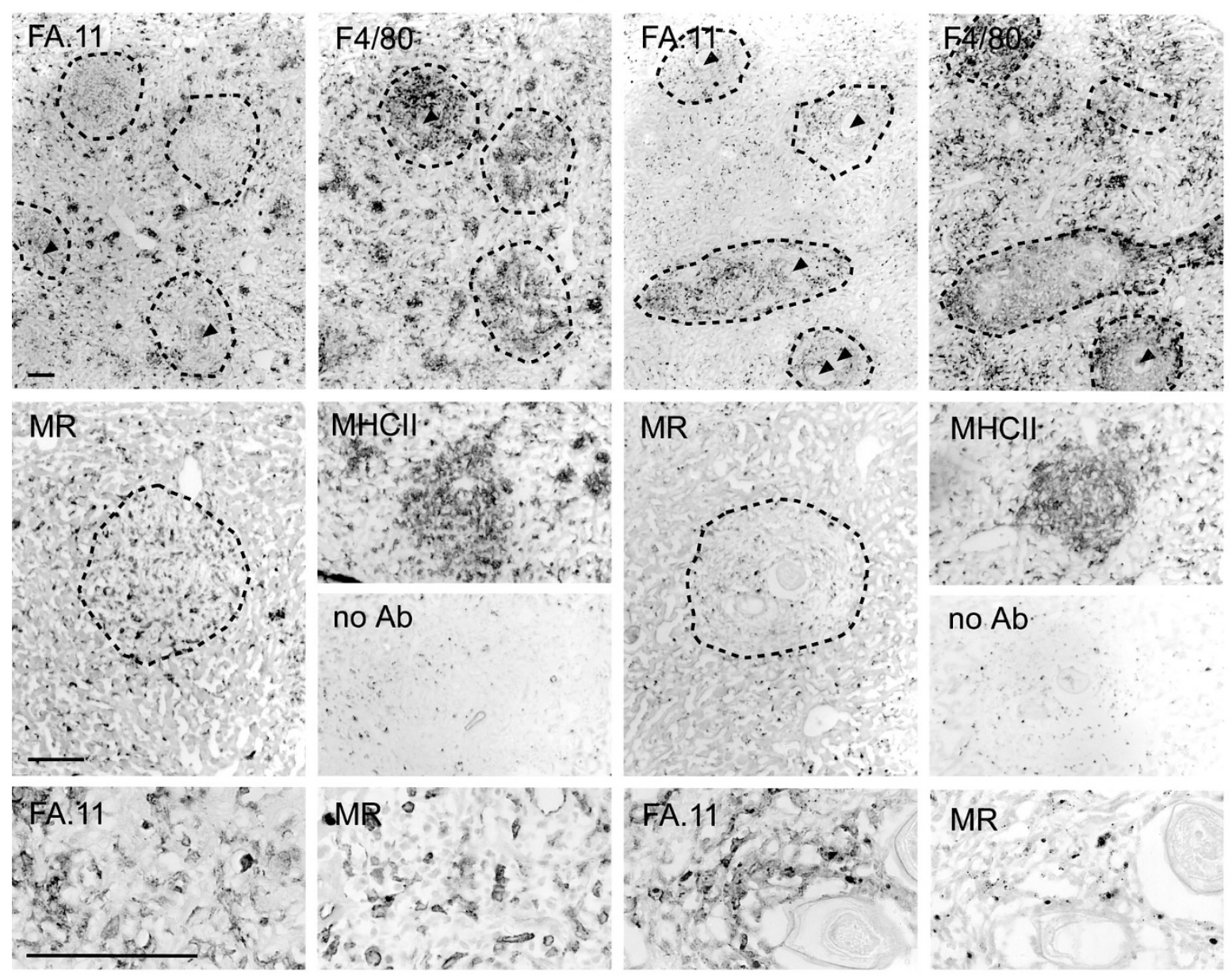

no $A b$
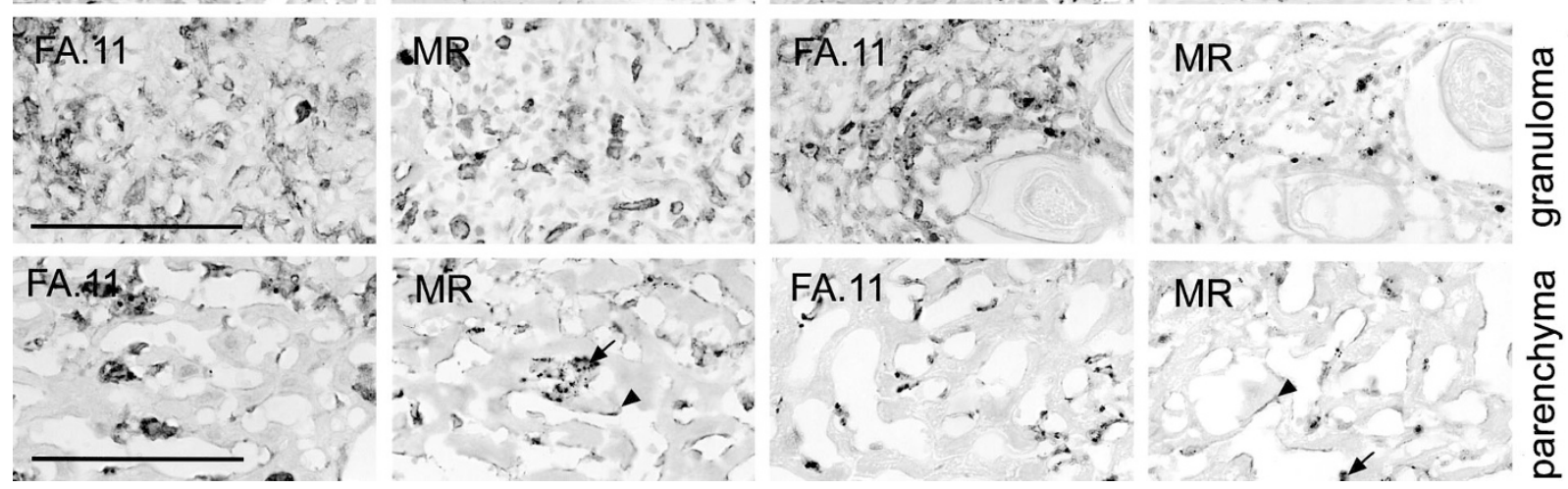

Figure 1.

Expression of M $\Phi$ markers in livers of infected wild-type (WT) and IL4R $\alpha-/$ - mice. Serial sections of WT and IL4R $\alpha-/-$ liver specimens were examined by immunocytochemistry using the antibodies indicated. In the upper panels, eggs are indicated by arrowheads. For clarity, granulomata in sections labeled for FA.11, $\mathrm{F} 4 / 80$, and mannose receptor (MR) are indicated with broken lines. Low magnification images of FA.11 and F4/80 staining show that granulomata in WT and IL4R $\alpha$ $-/-$ are rich in MФ and are roughly comparable in size. In the middle panels, expression of MR by cells in the parenchyma of both WT and IL4R $\alpha-/-$ is seen but only in the granuloma of the WT. Sections labeled "no Ab" were probed with secondary antirat Ab only. High magnification images of FA.11 expression in granulomata show that most positive cells have the spread morphology of mature $M \Phi$, but MR is only seen in the WT granuloma. Dark pigment presented in the IL4R $\alpha-/$ - section labeled for MR is schistosome-derived material that has been phagocytosed by M $\Phi$; the cells are clearly negative for MR. High magnification images of FA.11 staining in the parenchyma show that Kupffer cells are smaller in the IL4R $\alpha-/$ - livers. Kupffer cells (arrows) and hepatic endothelial cells (arrowheads) are positive for MR in both WT and IL4R $\alpha-/-$. Scale bars are shown for each row of images and are $50 \mu \mathrm{m}$. 
by MR and other non-opsonic receptors provide $M \Phi$ with a mechanism of internalising microbes in complement-poor sites such as the lung and at early stages of infection when specific lgG has not yet been generated. Given that many of its host-derived ligands are lysosomal enzymes and other inflammatory products, MR may assist in damping down inflammation at later stages of infection by clearing these products from the milieu (Shepherd et al, 1985). Indeed, MR-mediated clearance of lysosomal enzymes from the circulation has been well documented (Achord et al, 1978; Lee et al, 2002; Stahl et al, 1976).

Here we examine cytokine regulation of murine MR in granulomatous reactions driven by eggs of the trematode parasite, Schistosoma mansoni. Eggs are deposited in the mouse intestinal wall and also embolize in the liver in this model helminth infection, which is considered a reasonable model of human schistosomiasis (Brunet et al, 1998). In infected WT mice, the granulomatous response is Th2 polarized (Chiaramonte et al, 1999; Grzych et al, 1991; Pearce et al, 1991), whereas IL-4R $\alpha$ -/- mice mount a Th1-dominated cytokine response to S. mansoni eggs (Jankovic et al, 1999) and are totally unresponsive to both IL-4 and IL-13 (Mohrs et al, 1999). Alternatively activated $\mathrm{M} \Phi$ play an important role in immunomodulation of the granulomatous reaction (Villanueva et al, 1994) and in regulation of granulomatous immunopathology (Hess et al, 2001; La Flamme et al, 2001). We therefore undertook our study with due consideration to the role that MR might play in the egg granulomata, identifying ligands of MR in schistosome eggs and their secretions using an Fc-fusion protein bearing four of the carbohydrate recognition domains (CRDs) of MR.

\section{Results}

\section{MR Expression in Infected WT and IL-4Ro -/- Mice}

We examined tissues of BALB/c WT and IL-4R $\alpha-/-$ mice 7 weeks after infection with $S$. mansoni by immunocytochemistry. Egg deposition normally commences in the 6th week of infection, and in WT mice, the $\mathrm{T}$ cell response becomes Th2 polarized by the 7th week (Grzych et al, 1991). We examined the liver and small intestine as the major sites of egg deposition and the spleen and mesenteric lymph node $(\mathrm{mLN})$ as the major sites of egg antigen-specific $T$ and $B$ cell responses. Three mice of each type were examined, and no differences in the expression of MR were observed between individual mice of the same type. We also examined naïve IL-4R $\alpha-/-$ mice but found no differences compared with the naïve WT (not shown).

Liver. Our objective was to examine MR expression by mature $\mathrm{M} \Phi$ recruited to granulomata of infected WT and IL-4R $\alpha-/-$ mice. The pan-M $\Phi$ and monocyte marker, macrosialin (FA.11), was expressed weakly by cells throughout granulomata, which were present in the livers of both groups of infected mice (Fig. 1). On average, the granulomata area appeared slightly

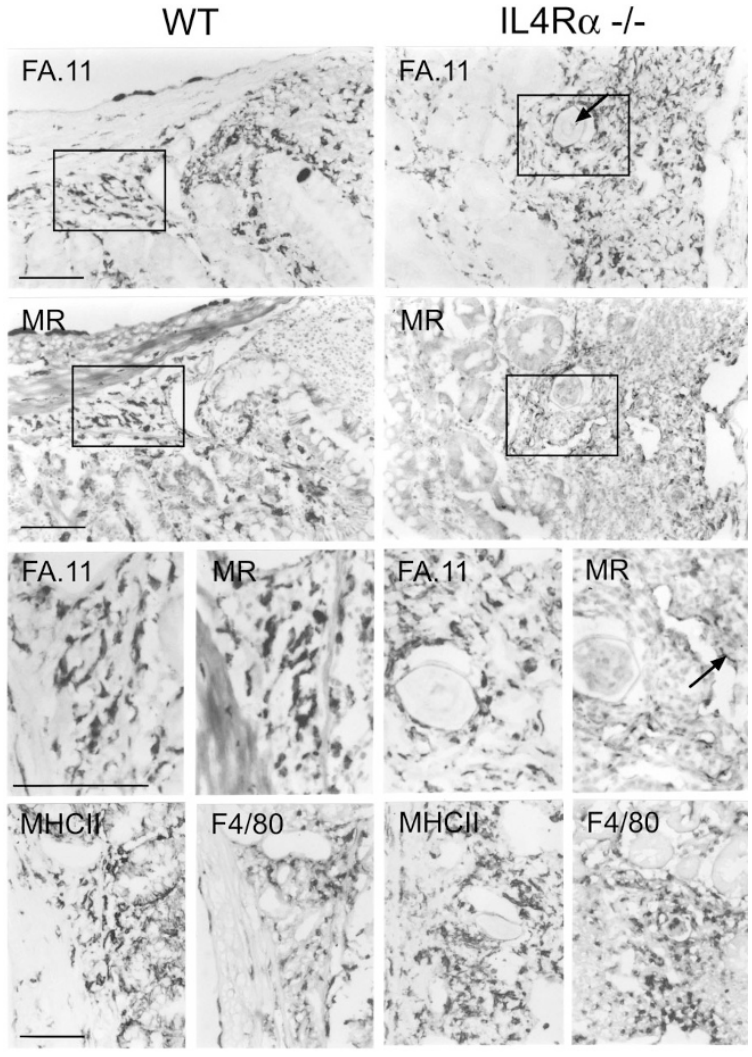

Figure 2.

Expression of M $\Phi$ markers in ilea of infected WT and IL4R $\alpha-/-$ mice. Serial sections of wild-type (WT) and IL4R $\alpha-/$ - ileum specimens were examined by immunocytochemistry using the antibodies indicated. $М \Phi$, labeled for FA.11, were abundant in granulomata, which formed close to the muscle wall. The arrow in the upper-right image indicates an embolized egg. Mannose receptor $(M R)$ was only detected in the WT granuloma. Boxed regions in the lower magnification images of FA.11 and MR labeling are shown at higher magnification below. Although $\mathrm{M} \Phi$ were clearly negative for MR in the IL4R $\alpha$ $-/-$, Iymphatic endothelium, indicated by the arrow, was labeled with the Ab. Lower magnification images of the inflammatory cells labeled with $\mathrm{MHCll}$ and F4/80 are also shown. Scale bars are shown for each row of images and are $50 \mu \mathrm{m}$.

smaller in IL-4R $\alpha-/-$ than WT liver sections when FA.11 staining was used to define the periphery of granulomata. Similarly, Jankovic and coworkers (1999) found IL-4R $\alpha$-/- liver granuloma volumes to be about one-third the size of WT using a quantitative histologic method that demonstrates eosinophils. To identify mature $M \Phi$, we detected expression of $F 4 / 80$, a $M \Phi$ differentiation antigen (Hirsch et al, 1981). All granulomata, in both WT and IL-4R $\alpha-/$ - livers, contained F4/80-positive cells, although the centers of some granulomata were weak or negative for F4/80 (Fig. 1). Because blood monocytes are recruited to granulomata from the periphery (King, 2001), the central F4/80-negative cells are most likely mature $M \Phi$ whose F4/80 has been down-regulated. Because MФ are abundant in both WT and IL-4R $\alpha-/-$ granulomata and are phenotypically similar with respect to F4/80 expression, a fair comparison of MR expression by granuloma $M \Phi$ from the two mouse strains can be made. 
Using a polyclonal $\mathrm{Ab}$, we found MR to be expressed only by the granuloma $M \Phi$ of WT and not IL-4R $\alpha-/$ - livers (Fig. 1). Because F4/80 labeling indicated that the $\mathrm{M} \Phi$ were mature, the absence of MR in IL-4R $\alpha-/-$ granulomata is unlikely to be due to inefficient maturation of MФ. In addition, most FA.11positive granuloma cells exhibit the spread morphology characteristic of differentiated $M \Phi$ rather than the rounded morphology of monocytes. Granulomata of WT and IL-4R $\alpha$-/- livers exhibited high levels of $\mathrm{MHCll}$ expression, indicating there is also no defect in $\mathrm{M} \Phi$ activation. Therefore, the lack of MR expression in IL-4R $\alpha-$ /- liver granulomata appeared relatively specific. Background reactivity of secondary Abs with liver sections was not detected, although some parasite-derived particulate matter was observed. Labeling for FA.11 indicated that $M \Phi$ had efficiently phagocytosed this.

In contrast to the lack of MR on granuloma $M \Phi$ in IL-4R $\alpha-$ - - livers, resident Kupffer cells and hepatic endothelial cells were positive for MR in both WT and IL-4R $\alpha-/-$ mice, paralleling that in naïve WT liver (Takahashi et al, 1998). In WT livers, clusters of FA.11positive cells were often observed, which may be due to local proliferation of Kupffer cells, but this was not detected in the IL-4R $\alpha-/-$ mice. This mirrors hepatocyte proliferation, which occurs in infected WT mice but only marginally in IL-4 -/- mice (La Flamme et al, 2001). Kupffer cells were also larger in the WT than IL-4R $\alpha-$ - - livers.

Small Intestine (lleum). MФ-rich granulomata were detected in small intestines of infected mice by reactivity with FA.11 $\mathrm{mAb}$ and appeared comparable in size in WT and IL-4R $\alpha-/-$ mice (Fig. 2). FA.11positive cells had the spread morphology of mature $M \Phi$. As in the liver granulomata, only the recruited $M \Phi$ of the WT gut expressed MR, although expression of MR by lymphatic endothelial cells was retained in the IL-4R $\alpha-/-$ mice, as it is in naïve WT mice (Linehan et al, 1999; Takahashi et al, 1998). Expression of F4/80 and $\mathrm{MHCll}$ by recruited $\mathrm{M} \Phi$ appeared similar in WT and IL-4R $\alpha-$ /- ileum. Background reactivity of secondary Abs was not detected (not shown).

Spleen and $m L N$. No differences in the expression of $\mathrm{MR}$ in spleens and $\mathrm{mLN}$ were noted between infected WT and IL-4R $\alpha-/-$ mice. In both, MR was restricted to the red pulp of the spleen, as it is in naïve mice (Linehan et al, 1999) (not shown). In mLN of infected mice, MR was expressed by medullary and marginal sinus $\mathrm{M} \Phi$ but not by subcapsular sinus $M \Phi$ (not shown). We noted a similarly restricted expression pattern of MR in naïve peripheral lymph nodes (Linehan et al, 1999).

\section{MR Expression in Egg Antigen-Sensitized and Egg-Challenged WT and IL-4Ro -/- Mice}

The finding that MR expression by granuloma but not resident $\mathrm{M} \Phi$ depended on intact IL-4R $\alpha$ signaling in $S$. mansoni-infected mice is a novel result. However, lipopolysaccharide (LPS) down-regulates MR protein expression by cultured MФ (Martínez-Pomares et al,

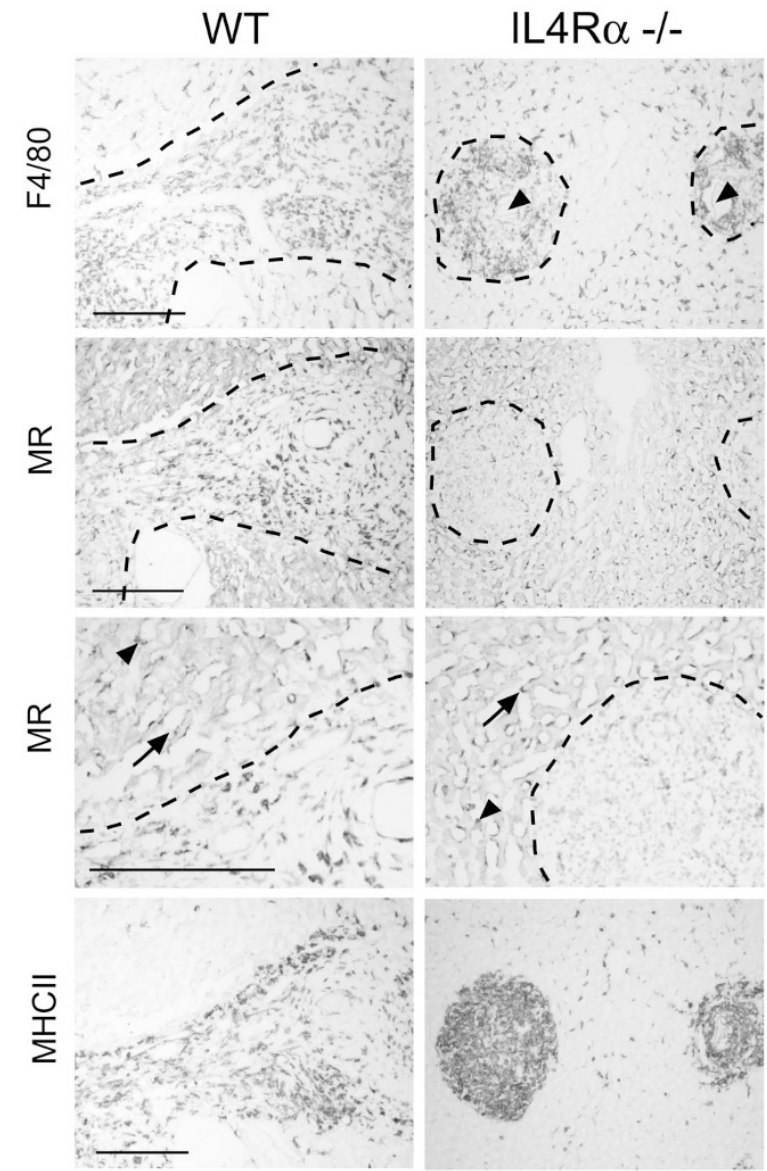

Figure 3.

Expression of M $\Phi$ markers in livers of egg-injected wild-type (WT) and IL4R $\alpha$ - /- mice. Serial sections of WT and IL4R $\alpha-/$ - liver specimens were examined by immunocytochemistry as indicated. $М \Phi$-rich granulomata, detected with F4/80 Ab, were found around schistosome eggs (indicated by arrowheads). Granuloma $\mathrm{M} \Phi$ were positive for mannose receptor $(M R)$ labeling only in WT. Granulomata are indicated with broken lines, and higher magnification images of single granulomata are shown. In these, MR-labeled Kupffer cells and hepatic endothelium are indicated with arrowheads and arrows, respectively. Dark pigment is due to positive staining only, as schistosome-derived debris was not found in this model. Granulomata of both WT and IL4R $\alpha-$ / - were positive for MHCII labeling. Scale bars are shown for each row of images and are $100 \mu \mathrm{m}$.

1998), and schistosome-infected IL-4/13-deficient mice suffer from high levels of circulating LPS, which may be due to leakage of the intestinal contents following the marked intestinal inflammation (Fallon et al, 2000).

We therefore sought a model of $S$. mansoni granuloma formation in which synchronized formation of granulomata would permit a short interval before collection of tissues and in which only the liver would receive eggs, so as to avoid intestinal pathology altogether. We injected live eggs via the superior mesenteric vein into mice that had previously been immunologically primed by injection of eggs into the peritoneal cavity. Because eggs induce the Th2 response in the normal infection (Grzych et al, 1991), we anticipated that this regimen would result in a Th2polarized response in WT mice. Tissues were collected 8 days after iv egg injection. We examined the 

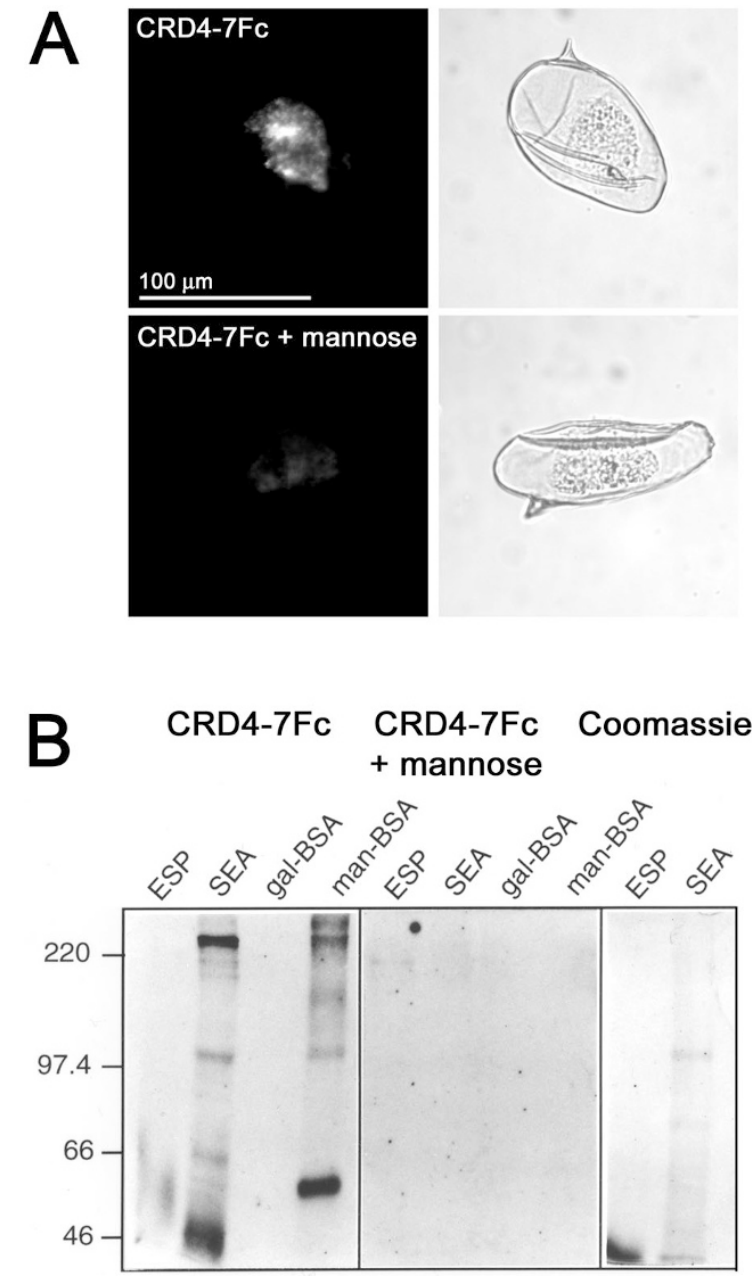

Figure 4.

Recognition of schistosome egg components and secretions by CRD4-7FC. (A) Hatched eggs were probed with CRD4-7Fc with and without mannose, and fluorescent microscope images (left) and corresponding phase contrast images (right) are shown. Sub-shell structures detected only upon rupture of the shell during hatching were labeled specifically with CRD4-7Fc. Background fluorescence when binding was competed with mannose was weak. (B) Egg-secreted proteins $(E S P)$ and soluble egg antigens $(S E A)$, separated by SDS-PAGE on nonreducing gels, were probed for CRD4-7Fc binding by lectin blotting. Man-BSA and Gal-BSA were included as positive and negative controls of CRD4-7FC binding, respectively. All bands were lost when CRD4-7Fc binding was competed with mannose. Coomassie staining was used to detect protein on gels.

2liver as the site of egg deposition and the spleen and $\mathrm{mLN}$ as the main sites of $\mathrm{T}$ and $\mathrm{B}$ cell responses. A total of six primed and injected mice, three each of WT and IL-4R $\alpha-/-$ mice, were examined, and no differences were observed between individual mice of the same genotype.

Liver. $М \Phi$-rich granulomata formed in livers of both egg-challenged WT and IL-4R $\alpha-/-$ mice (Fig. 3). F4/80 staining of granuloma $М \Phi$ was more homogeneous than in infected livers (Fig. 3), which may be related to the synchronicity of granuloma formation in the iv challenge model, and closely paralleled the expression of FA.11 (not shown). The resident Kupffer cells were also labeled with $\mathrm{F} 4 / 80 \mathrm{mAb}$; in this model we saw no clusters of F4/80-positive cells in the parenchyma, and Kupffer cells were comparable in size in WT and IL-4R $\alpha-/-$. Using MR5D3 mAb, we found MR to be expressed by Kupffer cells and hepatic endothelium in both WT and IL-4R $\alpha-/-$ mice, but the granuloma $M \Phi$ were positive for MR only in WT livers. Granulomata in both WT and IL-4R $\alpha-/-$ mice were filled with densely packed MHCll-positive cells, arguing against any defect in $\mathrm{M} \Phi$ activation in IL-4R $\alpha-/-$ mice.

Spleen and $m L N$. MR expression was restricted to the red pulp of the spleen in both egg-challenged WT and IL-4R $\alpha-/-$ mice (not shown), as it was in infected mice (this study) and naïve mice (Linehan et al, 1999). No differences in MR expression between the $\mathrm{mLN}$ of egg-challenged WT and IL-4R $\alpha-/-$ mice were noted (not shown).

\section{Recognition of Eggs and Egg Components by a Soluble MR-Fusion Protein, CRD4-7FC}

As $M R$ is able to bind to a diversity of microbial structures, we reasoned that in the context of the schistosome egg granulomata, MR may play a role in mediating $\mathrm{M} \Phi$ binding to or internalisation of egg components. To probe for ligands of MR in S. mansoni eggs, we used CRD4-7Fc, a fusion protein consisting of murine MR CRDs 4 through 7 fused to the Fc portion of human IgG1. CRD4-7Fc retains the same specificity for neoglycoconjugate and natural glycoprotein ligands as the natural soluble form of MR (Linehan et al, 2001; Martínez-Pomares et al, 1998). No binding of CRD4-7Fc was detected in intact eggs, examined by immunofluorescence microscopy, but internal structures were labeled in eggs from which the miracidia had hatched (Fig. 4A). CRD4-7Fc binding was carbohydrate-specific, being completely competed by mannose. CR-Fc, containing the cysteinerich domain of MR, did not bind to either hatched or unhatched eggs (not shown).

The CRD4-7Fc binding structures in hatched eggs had the appearance of the sub-shell envelope, a complex organ that is able to synthesize and secrete proteins (Ashton et al, 2001). Egg-secreted proteins (ESP) derived from the sub-shell envelope were concentrated from serum-free media in which mature eggs were maintained, and soluble egg antigens (SEA) were prepared by sonication and centrifugation of eggs. We probed ESP and SEA for MR ligands by lectin blotting of proteins separated by SDS-PAGE, and compared the pattern of bands with gels stained with Coomassie for protein (Fig. 4B). CRD4-7Fc reproducibly detected a species of approximately $55 \mathrm{kD}$ in ESP, which was not detected by protein staining. CRD4-7Fc also bound SEA fractions of approximately $265,120,65$, and $45 \mathrm{kD}$ in size. The 120-kD species may be the same as the abundant protein of the same molecular size detected by Coomassie staining. In all cases, binding of CRD4-7Fc was carbohydratespecific, because no background binding was detected when probe was incubated in the presence of mannose. No bands of $<45 \mathrm{kD}$ were detected by CRD4-7Fc binding, although bands were detected by Coomassie staining (not shown). 


\section{Discussion}

Heterogeneity of gene expression underpins the diversity of functions of $\mathrm{M} \Phi$ in innate and acquired immunity, tissue remodeling, and homeostasis. Global differences in gene expression exist between different tissue $M \Phi$ subsets and between $M \Phi$ treated with different cytokines or other stimuli in vitro (Gordon et al, 1992; Hamilton et al, 1999). The latter exhibit stochastic heterogeneity, on a cell-by-cell or clone-by-clone basis, with the probability of any particular inducible gene being transcribed dependent on its individual promoter elements (Ravasi et al, 2002). In this study, we examined the regulation of MR expression in S. mansoni infection of WT and IL-4R $\alpha-/-$ mice in situ by immunocytochemistry. This type of analysis permitted us to examine expression by different M $\Phi$ subsets, classified according to tissue location, in the relatively well-defined Th2- and Th1-type cytokine environments in WT and IL-4R $\alpha-/-$ mice, respectively.

MR, the prototype phenotypic marker of alternatively activated $M \Phi$ in vitro, was similarly expressed at high levels in the recruited granuloma $М \Phi$ in WT mice, but was not detected on granuloma $\mathrm{M} \Phi$ in IL-4R $\alpha-/-$ mice, either in a natural infection, or after iv delivery of eggs to the liver. IL-4R $\alpha-/-$ granuloma $M \Phi$, despite lacking MR expression, were positive for the differentiation antigen, $\mathrm{F} 4 / 80$, and the activation marker, $\mathrm{MH}-$ CII. Therefore, MR regulation appears to be analogous to in vitro studies in which IL-4 treatment of elicited murine peritoneal $M \Phi$ caused a 10-fold increase in MR expression and a 15-fold increase in endocytosis 2(Stein et al, 1992), while IL-13 caused a less potent up-regulation (Doyle et al, 1994). The total lack of responsiveness to either of these cytokines in our $\mathrm{IL}-4 \mathrm{R} \alpha-/-$ mice likely underlies their lack of MR induction. Furthermore, there are higher levels of the Th1 cytokine, IFN- $\gamma$, in infected IL-4R $\alpha-/-$ mice (Jankovic et al, 1999), which is significant because IFN- $\gamma$ causes a down-regulation of MR expression and endocytic activity in cultured murine and human MФ (Mokoena and Gordon, 1985; Schreiber et al, 1993). Our study represents the first in vivo validation of these in vitro studies.

Strikingly, the strict Th1/Th2 regulation of MR expression by cultured $\mathrm{M} \Phi$ and granuloma $\mathrm{M} \Phi$ was not reproduced by resident tissue $\mathrm{M} \Phi$ subsets or endothelial cells in vivo. Tissue $M \Phi$ that are negative for MR in naïve mice, such as those in the white pulp of the spleen and subcapsular sinus of lymph nodes (Linehan et al, 1999), did not express MR even in the strongly Th2 polarized environment of S. mansoniinfected WT mice. Likewise, cells positive for MR in naïve mice, including spleen red pulp and lymph node marginal sinus $M \Phi$, liver Kupffer cells, and hepatic endothelium, did not express detectably lower levels of MR in the strongly Th1-type environment of infected IL-4R $\alpha-/-$ mice compared with WT mice. It is, therefore, possible that the molecular cues that determine the phenotype of different tissue $М \Phi$ populations are quite unrelated to those that regulate elicited $\mathrm{M} \Phi$.
Because we did not find MR expression in granuloma $M \Phi$ in the Th1-dominated environment of $S$. mansoni-infected IL-4R $\alpha-/-$ mice, the question of whether $M R$ is expressed by recruited $M \Phi$ in other Th1-type infections must be raised. We found granuloma $M \Phi$ in the livers of WT mice infected with Mycobacterium bovis BCG to be negative for MR expression (S. A. Linehan, 2000, unpublished data). IFN- $\gamma$ treatment of in vitro $M \Phi$ permits an enhancement in MR phagocytic capability, despite a reduction in receptor expression (Maródi et al, 1993). However, if MR is not expressed by the appropriate inflammatory cells in vivo, its role in infections that generate Th1 responses may be confined to the initial interaction between resident cells and the invading microorganisms. Pulmonary infections in which the resident alveolar M $\Phi$ play a major role in microbial clearance are one scenario in which MR function may be of major importance throughout the duration of infection. The finding that reduced MR-dependent phagocytosis of Pneumocystis carinii by alveolar M $\Phi$ isolated from HIV patients correlates with increased clinical risk for $P$. carinii pneumonia supports this (Koziel et al, 1998). Our data suggest that MR is also suitably placed to function during the immune phase of Th2-type infections.

$\mathrm{M} \Phi$ are known to play important roles in schistosomiasis, which makes their function and phenotype especially worthy of study. The granulomatous response to schistosome eggs proceeds through a transitory Th0 phase, then becomes strongly Th2 dominated (Vella and Pearce, 1992). MФ contribute to this by inducing clonal anergy in egg antigen-specific Th1 cells by an unknown mechanism (Villanueva et al, 1994). MФ also play a role in regulating immunopathology. Th2-dependent induction of arginase- 1 expression by $M \Phi$ in schistosome infection counters the activity of residual iNOS by competition for the shared substrate of these enzymes, L-arginine (Hess et al, 2001). In infected Th2-deficient mutant mice, induction of arginase- 1 fails to occur, and iNOS is expressed at higher levels (Hess et al, 2001), apparently resulting in excess iNOS-dependent nitrosative tissue damage (Brunet et al, 1999; La Flamme et al, 2001), contributing to the increased morbidity and mortality of infected IL-4 -/- mice (Brunet et al, 1997). Differential regulation of iNOS and arginase- 1 by Th1/ Th2 cytokines in schistosome-infected mice (Hess et al, 2001) mirrors the expression profile observed previously in cultured M $\Phi$ and dendritic cells (Munder et al, 1999).

The ability of $\mathrm{M} \Phi$ to orchestrate Th1 responses and use toll-like receptors to sense microbial stimuli is well known (Aderem and Ulevitch, 2000), yet there is no information concerning whether interaction with schistosome-derived molecules stimulates $M \Phi$ to polarize the Th2 response. Analysis of the components secreted by live $S$. mansoni eggs and their interactions with $M \Phi$ will help to clarify this issue. Because $M \Phi$ express many receptors with partially overlapping specificities (Linehan et al, 2000), molecular approaches will be required to define receptor/ligand interactions. In our study we used a recombinant fusion protein bearing four of the CRDs of MR, CRD4$7 \mathrm{Fc}$, whose binding specificity have been previously 
validated (Linehan et al, 2001). CRD4-7Fc recognized a fraction secreted by mature eggs, which is likely pinocytosed by MR during the normal infection. Eggs secrete only a small number of proteins (Ashton et al, 2001), and these are able to induce granulomata when coupled to sepharose beads (Ashton, 2001). Egg secretions are also highly immunogenic, but antiglycan responses do not appear to be protective, so their elicitation may be a strategy of the schistosome egg to manipulate its host (Eberl et al, 2001). The availability of MR gene knockout mice (Lee et al, 2002) will permit further studies to address the role of MR in schistosomiasis.

In summary we have examined both the cytokine regulation of MR in murine schistosome infection and the parasite ligands of MR, which will be encountered by MR-expressing $M \Phi$ recruited to normal egg granulomata. By demonstrating a potent dependence of MR expression by granuloma M $\Phi$ on Th2 cytokines, we demonstrate the utility of MR as an in situ marker of alternative $\mathrm{M} \Phi$ activation among recruited cells. Our anti-MR mAb (Martinez-Pomares et al, 2003) will be useful tools for further study of alternatively activated $\mathrm{M} \Phi$ in a range of Th2-dependent pathologies.

\section{Materials and Methods}

\section{Mice and Parasites}

IL-4R $\alpha-/-$ mice on a pure BALB/c background (Mohrs et al, 1999) and WT control BALB/c mice were bred at Sir William Dunn School of Pathology, Oxford, and the Department of Biology, The University of York, in accordance with Home Office regulations. The Puerto Rican strain of Schistosoma mansoni was maintained in Biomphalaria glabrata snails and outbred MF1 mice.

\section{Antibodies and Fc-Fusion Proteins}

Rat monoclonal antibodies (Gordon et al, 1992) and MR Fc-fusion proteins were prepared in-house: antimacrosialin, clone FA.11; anti-MHCII, clone TIB120 (ATCC); anti-F4/80; anti-MR, clone MR5D3 (MartinezPomares et al, 2003); CR-Fc (Martínez-Pomares et al, 1996); and CRD4-7Fc (Linehan et al, 2001). The rabbit anti-MR polyclonal Ab (Linehan et al, 1999) was a kind gift from P.D. Stahl. Biotinylated secondary Abs, donkey antirat Ig $\mathrm{G}$ and donkey $\left.\mathrm{F}(\mathrm{ab})^{\prime}\right)_{2}$ antirabbit IgG were from Vector Laboratories (Burlingame, California). Biotinylated donkey antihuman IgG Fc, horseradish peroxidase conjugated mouse antihuman IgG $\mathrm{Fc}$, both $\left.\mathrm{F}(\mathrm{ab})_{2}\right)_{2}$, and streptavidin-cy3 were from Jackson ImmunoResearch Labs (West Grove, Pennsylvania).

\section{Schistosome Infection of Mice}

Mice were exposed percutaneously to approximately 80 S. mansoni cercariae via the shaved abdomen as described (Smithers and Terry, 1965). The liver, small intestine, spleen, and $\mathrm{mLN}$ were recovered for immunocytochemistry 7 weeks later.

\section{Schistosome Egg Challenge of Mice}

Viable S. mansoni eggs were extracted from the livers of 7-week-infected mice by trypsin digestion (Mountford et al, 1999). WT and IL-4R $\alpha-/-$ mice were first primed by injection of live $S$. mansoni eggs ip. Eight days later, when $T$ cell priming is assumed complete, live S. mansoni eggs were injected under anesthesia via the superior mesenteric vein (Wilson and Coulson, 1986), from where they are delivered to the liver. Spleen, liver, and $\mathrm{mLN}$ were collected after a further 8 days. In a related model of synchronized pulmonary egg-induced granuloma formation, $М \Phi$ are mature at this stage, being competent producers of TNF- $\alpha$ and expressing MHCII (Chensue et al, 1989). Due to surgeryrelated mortality of WT mice, a follow-up experiment was performed in which additional primed WT mice were subjected to egg injection 3 weeks after priming.

\section{Immunocytochemistry}

Tissues were collected following perfusion fixation of mice with $2 \%$ periodate-lysine-paraformaldehyde, and then postfixed in the same solution for 4 hours at $4^{\circ} \mathrm{C}$, and transferred to $20 \%$ sucrose in PBS overnight before freezing in OCT compound (BDH Chemicals, Merck) (Martínez-Pomares et al, 1996). Sections were cut at $6 \mu \mathrm{m}$, air-dried for 1 hour, and stored at $-20^{\circ} \mathrm{C}$. MR antigen was revealed by treatment of sections with $250 \mu \mathrm{g} / \mathrm{ml}$ protease type XXVII (Sigma) for 30 seconds (Takahashi et al, 1998). Sections were examined by immunocytochemistry using peroxidase/ diaminobenzidine tetrahydrochloride (Polysciences Inc., Northampton, United Kingdom) or alkaline phosphatase/Vector blue detection system (Vector Laboratories) as previously described (Linehan et al, 1999). Sections were counterstained with methyl green or Vector Red (Vector Laboratories) as appropriate. For all tissues, no background labeling in control sections probed with secondary Ab alone was detected.

\section{Probing of S. mansoni Eggs for Ligands of MR}

Live S. mansoni eggs recovered from the livers of infected mice (Mountford et al, 1999) were either immediately fixed in $1 \%$ paraformaldehyde in PBS for 20 minutes at room temperature or were incubated in day-old tap water until hatching had commenced and then fixed. Eggs were placed on cavity slides and incubated with 5\% normal rabbit serum for $30 \mathrm{~min}$ utes. They were probed for 1 hour with $10 \mu \mathrm{g} / \mathrm{ml}$ CRD4-7Fc in the presence or absence of $100 \mathrm{~mm}$ D-mannose as a specificity control, or $10 \mu \mathrm{g} / \mathrm{ml} \mathrm{CR-}$ Fc. They were then incubated for 30 minutes with biotinylated antihuman second $\mathrm{Ab}$, and then for 30 minutes with streptavidin-cy3. Abs were diluted in 5\% normal rabbit serum, and eggs were washed between each step. A calcium-containing buffer was used throughout (150 mm NaCl, $10 \mathrm{~mm}$ Tris $\mathrm{pH}$ 7.4, $10 \mathrm{~mm}$ $\mathrm{CaCl}_{2}$ ). Eggs were mounted in Aqua Polymount (Polysciences Inc.) 


\section{Lectin Blotting of S. mansoni Egg Components}

SEA and ESP were prepared as described (Ashton et al, 2001). Nonreduced proteins were subjected to electrophoresis by SDS-PAGE, transferred to nitrocellulose membranes, and subjected to lectin blotting using standard methods (Martínez-Pomares et al, 1998). CRD4-7Fc was used at $1 \mu \mathrm{g} / \mathrm{ml}$, with or without $100 \mathrm{~mm}$ D-mannose as a specificity control. Membranes were probed with the horseradish peroxidase-conjugated secondary $\mathrm{Ab}$, and signal was developed using enhanced chemiluminescence (ECL+, Amersham Life Science Ltd.). A calciumcontaining buffer was used throughout (150 mM NaCl, $10 \mathrm{~mm}$ Tris $\mathrm{pH} 7.4,10 \mathrm{~mm} \mathrm{CaCl}_{2}$ ). Mannose- and galactose-BSA (Sigma, St. Louis, Missouri) were used as positive and negative controls, respectively. Gels were also stained with Coomassie R-250 to detect protein.

\section{Acknowledgements}

We thank Mrs. Liz Darley for histology support, Dr. Peter D. Ashton for providing SEA and ESP, and Dr. Delyth M. Reid for preparing MR5D3 mAb.

\section{References}

Achord DT, Brot FE, Bell CE, and Sly WS (1978). Human $\beta$-glucuronidase: In vivo clearance and in vitro uptake by a glycoprotein recognition system on reticulo endothelial cells. Cell 15:269-278.

Aderem A and Ulevitch RJ (2000). Toll-like receptors in the induction of the innate immune response. Nature 406:782787.

Ashton PD. Characterisation of the egg secretions of Schistosoma mansoni [PhD thesis]. York, United Kingdom: University of York, 2001.

Ashton PD, Harrop R, Shah B, and Wilson RA (2001). The schistosome egg: Development and secretions. Parasitol 122:329-338.

Brunet LR, Beall M, Dunne DW, and Pearce EJ (1999). Nitric oxide and the Th2 response combine to prevent severe hepatic damage during Schistosoma mansoni infection. J Immunol 163:4976-4984.

Brunet LR, Dunne DW, and Pearce EJ (1997). IL-4 protects against TNF-alpha mediated cachexia and death during acute schistosomiasis. J Immunol 159:777-785.

Brunet LR, Dunne DW, and Pearce EJ (1998). Cytokine interaction and immune responses during Schistosoma mansoni infection. Parasitol Today 14:422-427.

Chensue SW, Otterness IG, Higashi GI, Shmyr Forsch C, and Kunkel SL (1989). Monokine production by hypersensitivity (Schistosoma mansoni egg) and foreign body (sephadex bead)-type granuloma macrophages. J Immunol 142:12811286.

Chiaramonte MG, Schopf LR, Neben TY, Cheever AW, Donaldson DD, and Wynn TA (1999). IL-13 is a key regulatory cytokine for Th2 cell-mediated pulmonary granuloma formation and IgE responses induced by Schistosoma mansoni eggs. J Immunol 162:920-930.
Doyle AG, Herbein G, Montaner LJ, Minty AJ, Caput D, Ferrara P, and Gordon S (1994). Interleukin 13 alters the activation state of murine macrophages in vitro: Comparison with interleukin 4 and interferon- $\gamma$. Eur $\mathrm{J} \mathrm{Immunol} \mathrm{24:1441-}$ 1445 .

Eberl M, Langermans JAM, Vervenne RA, Nyame AK, Cummings RD, Thomas AW, Coulson PS, and Wilson RA (2001). Antibodies to glycans dominate the host response to schistosome larvae and eggs: Is their role protective or subversive? J Infect Dis 183:1238-1247.

Falcone FH, Loke P, Zang X, MacDonald AS, Maizels RM, and Allen JE (2001). A Brugia malayi homolog of macrophage migration inhibitory factor reveals an important link between macrophages and eosinophil recruitment during nematode infection. J Immunol 167:5348-5354.

Fallon PG, Richardson EJ, McKenzie GJ, and McKenzie AN (2000). Schistosome infection of transgenic mice defines distinct and contrasting pathogenic roles for IL-4 and IL-13: IL-13 is a profibrotic agent. J Immunol 164:2585-2591.

Goerdt S and Orfanos CE (1999). Other functions, other genes: Alternative activation of antigen-presenting cells. Immunity $10: 137-142$.

Gordon S (2003). Alternative activation of macrophages. Nat Rev Immunol 3:23-35.

Gordon S, Lawson L, Rabinowitz S, Crocker PR, Morris L, and Perry H (1992). Antigen markers of macrophage differentiation in murine tissues. In: Russell $S$ and Gordon S, editors. Macrophage biology and activation, vol 181. Berlin: Spring-Verlag, 1-37.

Grzych J-M, Pearce E, Cheever A, Caulada ZA, Caspar P, Heiny S, Lewis F, and Sher A (1991). Egg deposition is the major stimulus for the production of Th2 cytokines in murine schistosomiasis mansoni. J Immunol 146:1322-1327.

Hamilton TA, Ohmori Y, Tebo JM, and Kishore R (1999). Regulation of macrophage gene expression by pro- and anti-inflammatory cytokines. Pathobiol 67:241-244.

Hess M, Modolell M, La Flamme AC, Schito M, Manuel Fuentes J, Cheever AW, Pearce EJ, and Wynn TA (2001). Differential regulation of nitric oxide synthase- 2 and arginase-1 by type1/type2 cytokines in vivo: Granulomatous pathology is shaped by the pattern of L-arginine metabolism. J Immunol 167:6533-6544.

Hirsch S, Austyn JM, and Gordon S (1981). Expression of the macrophage-specific antigen F4/80 during differentiation of mouse bone marrow cells in culture. J Exp Med 154:713725.

Jankovic D, Kullberg MC, Noben-Trauth N, Caspar P, Ward JM, Cheever AW, Paul WE, and Sher A (1999). Schistosomeinfected IL-4 receptor knockout (KO) mice, in contrast to IL-4 $\mathrm{KO}$ mice, fail to develop granulomatous pathology while maintaining the same lymphokine expression profile. J Immunol 163:337-342.

King CL (2001). Initiation and regulation of disease in schistosomiasis. In: Mahmoud AAF, editor. Schistosomiasis. London: Imperial College Press, 213-264.

Koziel H, Eichbaum Q, Kruskal BA, Pinkston P, Rogers RA, Armstrong MYK, Richards FF, Rose RM, and Ezekowitz RAB (1998). Reduced binding and phagocytosis of Pneumocystis carinii by alveolar macrophages from persons infected with HIV-1 correlates with mannose receptor downregulation. $\mathrm{J}$ Clin Invest 102:1332-1344. 
La Flamme AC, Patton EA, Bauman B, and Pearce EJ (2001). IL-4 plays a crucial role in regulating oxidative damage in the liver during schistosomiasis. J Immunol 166:1903-1911.

Lee SJ, Evers S, Roeder D, Parlow AF, Risteli J, Risteli L, Lee YC, Feizi T, Langen H, and Nussenzweig MC (2002). Mannose receptor-mediated regulation of serum glycoprotein homeostasis. Science 295:1898-1901.

Linehan SA, Martínez-Pomares L, da Silva RP, and Gordon S (2001). Endogenous ligands of the carbohydrate recognition domains of the mannose receptor in murine macrophages, endothelial cells and secretory cells: Potential relevance to inflammation and immunity. Eur J Immunol 31:1857-1866.

Linehan SA, Martínez-Pomares L, and Gordon S (2000). Macrophage lectins in host defence. Microbes Infect 2:279288.

Linehan SA, Martínez-Pomares L, Stahl PD, and Gordon S (1999). Mannose receptor and its putative ligands in normal murine lymphoid and non-lymphoid organs. In situ expression of mannose receptor by selected macrophages, endothelial cells, perivascular microglia and mesangial cells, but not dendritic cells. J Exp Med 189:1961-1972.

Maródi L, Schreiber S, Anderson DC, MacDermott RP, Korchak HM, and Johnston RBJ (1993). Enhancement of macrophage candidacidal activity by interferon- $\gamma$. Increased phagocytosis, killing, and calcium signal mediated by a decreased number of mannose receptors. J Clin Invest 91:2596-2601.

Martínez-Pomares L, Kosco-Vilbois M, Darley E, Tree P, Herren S, Bonnefoy J-Y, and Gordon S (1996). Fc chimeric protein containing the cysteine-rich domain of the murine mannose receptor binds to macrophages from splenic marginal zone and lymph node subcapsular sinus and to germinal centers. J Exp Med 184:1927-1937.

Martínez-Pomares L, Mahoney JA, Káposzta R, Linehan SA, Stahl PD, and Gordon S (1998). A functional soluble form of the murine mannose receptor is produced by macrophages in vitro and is present in mouse serum. J Biol Chem 273: 23376-23380.

Martinez-Pomares L, Reid DM, Brown GD, Taylor PR, Stillion RJ, Linehan SA, Zamze S, Gordon S, and Wong SYC (2003). Analysis of mannose receptor regulation by IL-4, IL-10 and proteolytic processing using novel monoclonal antibodies. J Leukoc Biol 73:604-613.

Mohrs M, Ledermann B, Köhler G, Dorfmüller A, Gessner A, and Brombacher F (1999). Differences between IL-4- and IL-4 receptor $\alpha$-deficient mice in chronic leishmaniasis reveal a protective role for IL-13 receptor signaling. J Immunol 162:7302-7308.

Mokoena T and Gordon S (1985). Human macrophage activation. Modulation of mannosyl, fucosyl receptor activity in vitro by lymphokines, gamma and alpha interferons, and dexamethasone. J Clin Invest 75:624-631.

Montaner LJ, da Silva RP, Sun J, Sutterwala S, Hollinshead M, Vaux D, and Gordon S (1999). Type 1 and type 2 cytokine regulation of macrophage endocytosis: Differential activation by IL-4/IL-13 as opposed to IFN-gamma or IL-10. J Immunol 162:4606-4613.

Mountford AP, Coulson PS, Cheever AW, Sher A, Wilson RA, and Wynn TA (1999). Interleukin-12 can directly induce T-helper 1 responses in interferon-gamma (IFN-gamma) receptordeficient mice, but requires IFN-gamma signaling to downregulate T-helper 2 responses. Immunology 97:588-594.
Munder M, Eichmann K, Morán JM, Centeno F, Soler G, and Modolell M (1999). Th1/Th2-regulated expression of arginase isoforms in murine macrophages and dendritic cells. J Immunol 163:3771-3777.

Pearce EJ, Caspar P, Grzych J-M, Lewis FA, and Sher A (1991). Downregulation of Th1 cytokine production accompanies induction of Th2 responses by a parasitic helminth Schistosoma mansoni. J Exp Med 173:159-166.

Pontow SE, Kery V, and Stahl PD (1992). Mannose receptor. Int Rev Cytol 137B:221-244.

Raes G, De Baetselier P, Noel W, Beschin A, Brombacher F, and Hassanzadeh GG (2002). Differential expression of FIZZ1 and Ym1 in alternatively versus classically activated macrophages. J Leukoc Biol 71:597-602.

Ravasi T, Wells C, Forrest A, Underhill DM, Wainwright BJ, Aderem A, Grimmond S, and Hume DA (2002). Generation of diversity in the innate immune system: Macrophage heterogeneity arises from gene-autonomous transcriptional probability of individual inducible genes. J Immunol 168:44-50.

Schreiber S, Perkins SL, Teitelbaum SL, Chappel J, StahI PD, and Blum JS (1993). Regulation of mouse bone marrow macrophage mannose receptor expression and activation by prostaglandin E and IFN $\gamma$. J Immunol 151:4973-4981.

Shepherd VL, Konish MG, and Stahl PD (1985). Dexamethasone increases expression of mannose receptors and decreases extracellular lysosomal enzyme accumulation in macrophages. J Biol Chem 260:160-164.

Smithers SR and Terry RJ (1965). The infection of laboratory hosts with cercariae of Schistosoma mansoni and recovery of the adult worms. Parasitol 55:695-700.

Stahl PD, Six H, Rodman JS, Schlesinger P, Tulsiani DRP, and Touster O (1976). Evidence for specific recognition sites mediating clearance of lysosomal enzymes in vivo. Proc Nat Acad Sci USA 11:4045-4049.

Stein ML, Keshav S, Harris N, and Gordon S (1992). IL-4 potently enhances macrophage mannose receptor (MMR) activity in mouse peritoneal macrophages. J Exp Med 176: 287-292.

Takahashi K, Donovan MJ, Rogers RA, and Ezekowitz RAB (1998). Distribution of murine mannose receptor expression from early embryogenesis through to adulthood. Cell Tissue Res 292:311-323.

Vella AT and Pearce EJ (1992). CD4 ${ }^{+}$Th2 response induced by Schistosoma mansoni eggs develops rapidly, through an early, transient, Th0-like stage. J Immunol 148:2283-2290.

Villanueva POF, Harris TS, Ricklan DE, and Stadecker MJ (1994). Macrophages from schistosomal egg granulomas induce unresponsiveness in specific cloned Th-1 lymphocytes in vitro and down-regulated schistosomal granulomatous disease in vivo. J Immunol 152:1847-1855.

Wilson RA and Coulson PS (1986). Schistosoma mansoni: Dynamics of migration through the vascular system of the mouse. Parasitol 92:83-100. 